\title{
AN EXPERT SYSTEM FOR DEFICIT IRRIGATION IN THE NORTH CHINA REGION BASED ON PDA
}

\author{
Jianhui Lin ${ }^{1}$, Yurui Sun ${ }^{1 *}$, Shaoyun Feng ${ }^{2}$, Risheng Ding ${ }^{2}$, Qiushi Hou ${ }^{1}$ \\ 1 College of Information and Electronic Engineering, China Agricultural University, Beijing, \\ 100083, People Republic of China \\ 2 College of Water Conservancy and Civil Engineering, China Agricultural University, \\ Beijing, 100083, People Republic of China
}

Abstract: Deficit Irrigation (DI) is an advanced method of irrigation and this method was used in the north region of China more and more. But it is also a complex method for using. To allow this method to be used facilely, especially in field, an expert system (ES) for deficit irrigation based on Personal Digital Assistant (PDA) has been developed. The system structure and components such as database, knowledge base and their functions are described. This expert system is suitable for north of China and it also will be used in other regions by adding corresponding data to the knowledge bases.

Key words: Expert System, Deficit Irrigation, Personal Digital Assistant, North China

\section{INTRODUCTION}

It is known that agriculture is the major user of water resource which account for $70 \%$ of total water use and irrigation water use account for more than $90 \%$ of agriculture water use ( $\mathrm{Ma}, 1998)$. But in some places where water resources are limited, available water is the most important factor limiting crop yields. For example in the Northwest China region, because of the severe lack of water, this region which account for $30 \%$ of Chinese total area only yields $7.4 \%$ of national grain output, and the water use efficiency is only $30 \%$ to $40 \%$ (Shangguan, Shao and Xue, 2001). When the available 
water supply is severely limited, water deficit will be unavoidable during some periods of crop growth. How to improve water use efficiency and to maintain crop yield under water deficit have become cosmopolitan problems. And just for these reasons, since 1960s, deficit irrigation which also was named Limited Irrigation has been studied in America. In a short time, this method has been studied and applied around the world. Deficit irrigation means that the soil water deficit is controlled at certain stages of crop growth. Studies on the effects of deficit irrigation on crop yield and water use efficiency show that crop yield can be largely maintained and product quality can, in some cases, be improved while substantially reducing irrigation volume. But in these cases, scheduling of irrigation timing and volume then becomes more complex, because irrigation decisions have to be based not only on the relationships among grain yield, crop growing phase and crop water use, but also on water availability (Kang, Shi and Zhang, 2000, Kang et al., 2002). It poses a major challenge for any attempt in developing a computer-based system capable for providing accurate decision.

The rapid increase of PDA application and the cost-effective growth of its key enabling technologies are revolutionizing information technology and creating unprecedented opportunities for developing small portable application. Advantages of PDA technologies have offered new opportunities for enhancing traditional decision support system and expert system. With the development of Expert System and Embedded technology, PDA is able to play some important roles that normally require human actions. A few of expert systems based on PDA are reported in literature. It appears that the research and development of expert system based on PDA are still in their early stage (Tu, Wang and Zhao, 2000, Chen et al., 2002,).

Most of the existing agricultural expert systems are developed for personal computers, such as CIMIS, an expert system for irrigation evaluation developed by California State University, U.S.A (Xie et al., 1992), and WRMDSS, an expert system for water resource management developed by Carolina University, U.S.A (Johuson, 1986). All of these systems have a disadvantage that they can not be used in field facilely. A portable expert system for deficit irrigation based on PDA called ESDI has been developed by Information and Electronic Engineering College of China Agriculture University. This expert system is suitable for farmer, agriculture technician or manager to come to a decision on-the-spot field with a user-friendly interface. It contains a large amount of weather data, hydrology data, crop water needed data and water resource data, which are used to make an irrigation decision. At the end of this paper, some experiments of developing portable expert system and suggestions of improving the development are discussed. 


\section{DEFICIT IRRIGATION METHOD}

With increasing municipal and industrial demands for water, the allocation of water for agriculture is decreasing steadily. The major agricultural use of water is for irrigation, which, thus, is affected by decreased supply. Therefore, innovations are needed to increase the efficiency of use of the water that is available. Deficit (or regulated deficit) irrigation is one way of maximizing water use efficiency (WUE) for higher yields per unit of irrigation water applied: the crop is exposed to a certain level of water stress either during a particular period or throughout the whole growing season. The expectation is that any yield reduction will be insignificant compared with the benefits gained through diverting the saved water to irrigate other crops (Kirda, 2002). The research of the model of crop response to water is the core of the deficit irrigation, which is significant for the application of deficit irrigation. Early in the 1968, Jensen gave the Jenson model which not only presents the relationship between crop yield and water, but also confirm the effect of water supply to crop yield. After then, more models were studied such as Hiler \& Clark model, Minhas model, Stewart model, Doorenbos \& Kassam model and Sudar model et al (Zhao, Cai and Zhang, 2004). Among these models, Jensen model is the most suitable model for north China region according to more than three decades research. Jensen model is shown as (Chen and Kang, 1994):

$$
\frac{Y_{a}}{Y_{m}}=\prod_{i=1}^{n}\left(\frac{E T_{a i}}{E T_{m i}}\right)^{\lambda_{i}}
$$

where $Y_{a}$ and $Y_{m}$ are expected and maximum crop yield, corresponding to $E T_{a i}$ and $E T_{m i}$, actual and maximum evapotranspiration in stage $i$, respectively; $\lambda_{i}$ is the sensitivity index of water lack in stage $i$.

\section{DATA COLLECTION}

In resent years, many techniques have been developed for data collection and knowledge acquisition. Some commonly used approaches are interviews, observations, finding from literature, taking experts through case studies and rule inducting by machines. In the development of ESDI, a multiple data collection method has been used. The data collection process consists of user surveys and interviews, expert interviews, finding data from literature and data transform by computer. 
User surveys and interviews: A large number of data have been collected from farms then the needs of farm have been understood.

Expert interviews: Some irrigation experts from Beijing, Henan province and Shanxi province took part in interviews. They provided the basic rule of knowledge base.

Finding data from literature: All of the weather data, hydrology data, crop water need data and water resource data were collected from literature which located in water conservancy, weather bureau and bureau of agriculture et al. It can ensure the accuracy of the data.

Data transform: At first data were collected with Excel spreadsheets or word documents. But in expert system the database would use MS Pocket Access. A special program was developed for transforming data into suitable format.

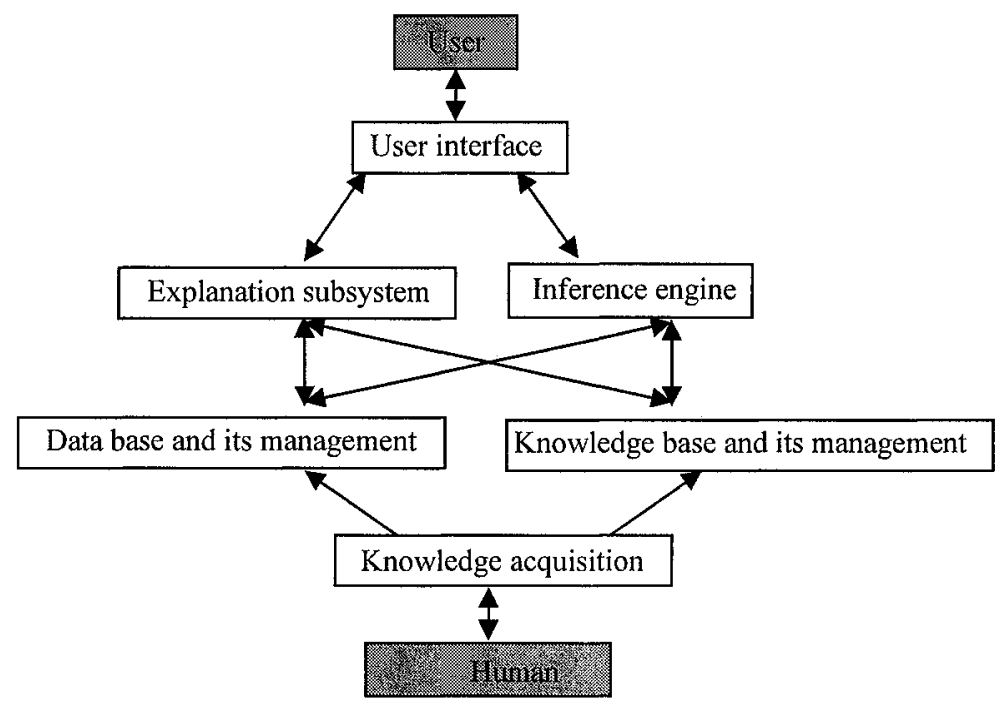

Figure 1. System Architecture

\section{SYSTEM DESIGN AND DEVELOPMENT}

The expert system for deficit irrigation consists of a data base, a knowledge base, inference engine, explanation subsystem, knowledge acquisition and user interface. The system architecture is showed in Figure 1. 


\subsection{Software Selection}

Traditional ESs were developed for stand-alone computers and a number of development tools are available for developing traditional ESs. With the rapid development of the PDA, more ESs based on PDA are beginning to emerge. At the time when the expert system for deficit irrigation was developed, no suitable tool for ESs based on PDA was available. And during the development of the expert system based on PDA, it must be considered that the limited hard ware resource is available. Thus ESDI was developed using a mixture of embedded technique and visual programming language. So that MS WinCE, MS eMbedded Visual C++ 4.0, MS Pocket Access are selected in the developing.

\subsection{Data Base}

Database plays an important role in the development of ESDI. It is used for storing all the information needed for irrigation decision. The database is mostly designed with MS Pocket Assess which is only used on PDA. Most of the data were initially collected from irrigation experts, books and documents of water bureau et al. with Excel spreadsheets or Word documents. These Excel spreadsheets and Word documents were translated into Pocket Assess by system developers. The database includes weather database, hydrology database, crop water need database and water resource database.

\subsection{Knowledge Base}

The knowledge base contains all the rules for the irrigation decision. Each rule has two sections-a field or crops case selection and a corresponding data selection in the form of "IF field or crop case THEN selected corresponding data". For example if the crop is cotton then the number of Jensen model stages is four.

\subsection{Inference Process}

The inference process is showed in Figure 2. After user inputs some basic parameters, such as crop type, region and available water for irrigation, ESDI will find matched data from database. First, number of irrigation stage, sensitivity index and intending depth of wetted soil will be determined from crop water need database. Second, the max evapotranspiration will be calculated according to weather database and crop water need database. 
Third, according to the knowledge base the model will be selected. At last, the model will be resolved using the algorithm of dynamic programming. With the output of the irrigation schedule, some detail interpretation will be given to the user, such as why irrigation water should be limited in a certain irrigation stage.

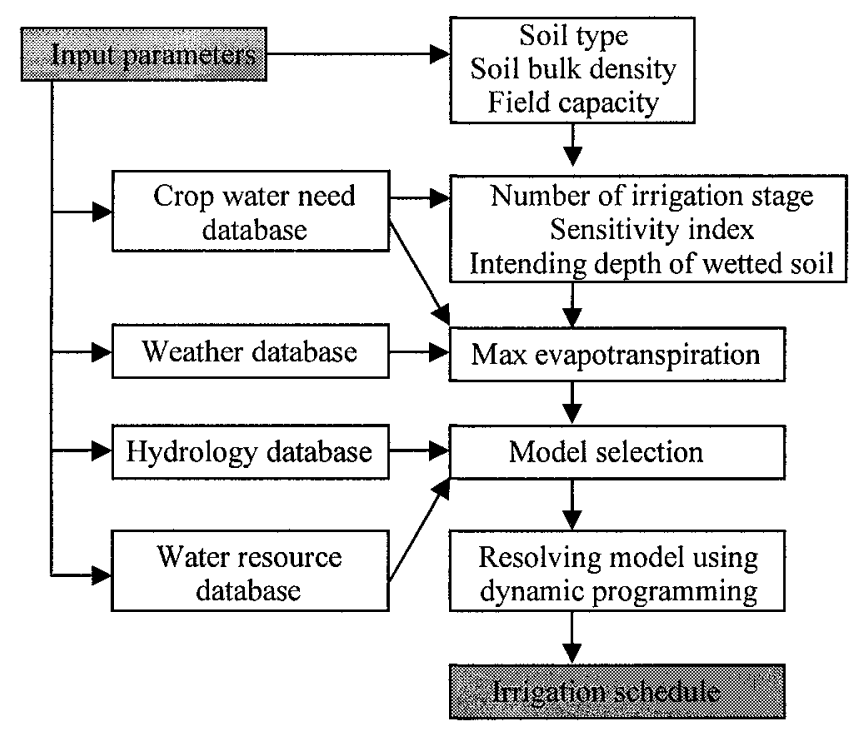

Figure 2. Inference Process

\subsection{User Interface}

Because the screen of PDA is so small, user interface can not display as many information as personal computer in one screen. The model of display was designed as multi-layer screens. Most of the information was displayed by text, table or picture. The displayed information includes irrigation schedule, max evapotranspiration of every stage and the proportion between actual production and potential production. Some detail explanations of result are also displayed for user.

\section{CONCLUSION}

ESDI is an expert system that presents the result schedule of deficit irrigation to a farm or field manager. In our opinion, it provides us a more extended environment to use this expert system in the irrigation decision process. And as a try to develop expert system based on PDA, we can draw 
the following conclusions from our experiments and the learning of the development of ESDI :

- PDA is an embedded system whose hardware resource is limited, so how to use available hardware resource effectively must be considered during the process to develop expert system. For example, how to design the format of display to suit the small screen and how to display the picture clearly.

- As an expert system for irrigation, the collection of credible data is very important. How to increase new data into the system is a challenge in the use of ESDI. A subsystem for increasing new data could be integrated for data update. This subsystem could transmit data between PDA and personal computer with suitable format.

- How to improve the speed of the system is a difficult problem because the algorithm of dynamic programming is very complex and the arithmetic speed of the microprocessor of PDA is more lower than personal computer.

In summary, the rapid development of PDA technology has changed the way in which an expert system can be developed and distributed. The essence of an expert system is to simulate experts and distribute expert knowledge without experts. These benefits have been greatly enhanced with the emergence of PDA. However, the development of expert system based on PDA has also brought some challenges in the methodological and technological aspect. More researches should be carried out to address the challenges posted by developing and implementing expert system based on PDA.

\section{ACKNOWLEDGEMENTS}

The research was funded by the National High Science and Technology Development Plan (863 Plan) in China (project number: 2002AA2Z4031). We would like to thank many domain experts from Beijing, Henan and Shaxi province, for their cooperation and support.

\section{REFERENCES}

[1]. Chen Liping et al., 2002, Research and development of a development platform on handheld personal computer for agriculture expert system (in Chinese), Transaction of CSAE, 18(3): 142--145

[2]. Chen Yaxian, Kang Shaozhong, 1994, The theory of deficit irrigation (in Chinese), Beijing, Water and Hydropower Press. 
[3]. Johuson L. E., Water resource management decision support system, Journal of water resource planning and management, 112(3): 308-325

[4]. Kang Shaozhong, Shi Wenjuan, Zhang Jianhua, 2000, An improved water use efficiency for maize grown under regulated deficit irrigation, Field crops research, 67: 207--214

[5]. Kang Shaozhong et al., 2002, Effects of limited irrigation on yield and water use efficiency of winter whet in the loess plateau of China, Agricultural water management, 55: 203-216

[6]. Kirda C., 2002, Deficit irrigation scheduling based on plant growth stages showing water stress tolerance, in FAO, Deficit irrigation practices, Rome, 3-10

[7]. Ma Zhongming, 1998, Studies on the Relationship between crop and water under limited irrigation (in Chinese), Agricultural Research in the Arid Areas, 16(2): 7579

[8]. Shangguan Zhouping, Shao mingan, Xue Zengzhao, 2001, Decision support system of water requirement forecast for dryland crop (in Chinese), Transactions of CASE, 17(2): $42-46$

[9]. Tu Yunhua, Wang Donghui and Zhao Chunjiang, 2000, The research and development of a development platform on HPC/PDA for agricultural expert system based on Windows CE (in Chinese), High Community Technology, 10: 28-31

[10]. Xie Guixu et al., 1992, Study of agriculture water save and management in American California (in Chinese), Irrigation and water conservancy and mini hydro, 2: $40-43$

[11]. Zhao Yong, Cai Huanjie, Zhang Chaoyong, 2004, The status and problems of deficit irrigation research (in Chinese), China Rural Water and Hydropower, 4: 14 